\title{
Assessment of cardiovascular sympathetic function tests in premenstrual syndrome patients visiting tertiary care hospital: A case-control study
}

\author{
Megha Kulshreshtha', Naveen Gaur'2, Varuna Gupta ${ }^{3}$, Satyanath Reddy Kodidala ${ }^{4}$ \\ ${ }^{1}$ Assistant Professor, Department of Physiology, Subharti Medical College, Meerut, Uttar Pradesh, India, ${ }^{2}$ Professor \\ and Head, ${ }^{4}$ Assistant Professor, Department of Physiology, ${ }^{3}$ Assistant Professor, Department of Microbiology, Kanti \\ Devi Medical College Hospital and Research Centre, Mathura, Uttar Pradesh, India
}

\section{A B S T R A C T}

Background: Premenstrual syndrome (PMS) is a stress-induced disorder and is showing a rising prevalence but its etiopathogenesis is not yet understood. Stress disturbs the balance of the sympathetic and parasympathetic nervous system. Alteration in heart rate and blood pressure is the most important physiological response following stress-induced sympathetic changes. Aims and Objectives: The present study was designed to test the hypothesis of an association between sympathetic functions and PMS and to observe the degree of changes (if any) in these sympathetic functions. The study also aims to provide timely interventions to prevent the development of cardiovascular complications and improve lifestyle. Materials and Methods: A Menstrual Distress Questionnaire was used to evaluate physical, emotional, and behavioral symptoms accompanying the menstrual cycle of the subjects who fulfilled the inclusion criteria. Based on the scores obtained by their questionnaire, subjects with the higher scores formed the PMS group, while the agematched females with low score served as controls. Cardiovascular sympathetic functions were assessed by standardized, simple, non-invasive tests which included Handgrip test and orthostatic hypotension test. Unpaired Student's t-test was used for statistical analysis. Results: The results revealed that the sympathetic reactivity is insignificantly higher in PMS group during the follicular phase. During the luteal phase, sympathetic activity is significantly increased. Conclusion: PMS involves psychoneuroendocrinal turmoil, thus early screening of high-risk groups and interventions such as relaxation techniques and lifestyle modification can prevent further cardiovascular complications in patients of high sympathetic responses.

Key words: Hand grip test; Orthostatic hypotension test; Premenstrual syndrome;

Sympathetic function tests

\section{Access this article online}

Website:

http://nepjol.info/index.php/AJMS DOI: 10.3126/ajms.v12i12.39593

E-ISSN: 2091-0576

P-ISSN: 2467-9100

Copyright (c) 2021 Asian Journal of Medical Sciences

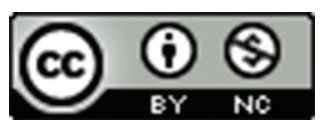

This work is licensed under a Creative Commons Attribution-NonCommercial 4.0 International License.

\section{INTRODUCTION}

Premenstrual syndrome (PMS) is a major clinical entity affecting a large segment of the female population. PMS is a psychoneuroendocrine disorder describing a range of emotional, behavioral, and physical symptoms that occur during the luteal phase of the menstrual cycle and abate following menstruation. ${ }^{1} \mathrm{Up}$ to $18 \%$ of women have severe PMS that causes significant impairment in term of family/ social relationships and quality of $l i f e .{ }^{2}$ Some studies show higher heart rate (HR), greater skin conductance, or greater norepinephrine levels throughout the menstrual cycle ${ }^{3,4}$ or just in the late-luteal phase in women with severe $\mathrm{PMS}^{5}$ others show no differences in these measures compared to controls. ${ }^{6}$ Many behavioral and neurological symptoms such as headache, malaise, nervous irritability, and emotional instability are reported during the premenstrual phase. $^{7}$ PMS is a stress-induced disorder and is showing a rising 
prevalence but its etiopathogenesis is not yet understood. Stress disturbs the balance of the sympathetic and parasympathetic nervous system. Alteration in HR and blood pressure (BP) is the most important physiological response following stress-induced sympathetic changes. To the best of our knowledge, only a few studies have well documented the associations of sympathetic functions with two phases of the menstrual cycle and in relation to the presence of premenstrual symptoms. This stipulated the need of performing sympathetic function tests particularly in the north-western region of Uttar Pradesh. Thus, keeping the aforementioned background in mind, the present study was designed to test the hypothesis of an association between sympathetic functions and PMS, to reconfirm if the activity of the sympathetic nervous system is altered during PMS and also to know its magnitude during the menstrual cycle of women with different grades of premenstrual symptomatology. The study also aims to provide timely interventions to control the further progression of symptoms.

\section{Aims and objectives}

To find the association between sympathetic functions and premenstrual syndrome. An association between sympathetic functions and premenstrual syndrome and to observe the degree of changes.

\section{MATERIALS AND METHODS}

This case-control study was conducted in the Department of Physiology, LLRM Medical College and associated Hospital, Meerut, between October 2010 and April 2012. The procedures were non-invasive and were approved by the Institutional Ethical Committee of LLRM Medical College. The experiment protocol was explained to the participants and informed written consent was obtained.

\section{Type of study}

This is an observational study of case-control design.

\section{Study area and setting}

This study was conducted at LLRM Medical College and associated Hospital, Meerut.

\section{Study period}

The study was carried out for a period of 8 months. The data collection phase was from January 2011 to December 2011. Data analysis and interpretation were done from January 2012 to February 2012. Final reporting was done from March 2012 to May 2012.

\section{Study population}

The study population included all the female patients visiting gynecology OPD.

\section{Study unit}

All the female patients in the study population were diagnosed as cases of PMS. These subjects served as a case group. The control group included age-matched healthy participants.

\section{Sample size}

The study was conducted on 45 subjects. Out of 21 were cases and 24 were control group.

\section{Sampling technique}

The sample was selected from the study population using the judgmental/purposive sampling technique.

\section{Selection criteria}

\section{Inclusion criteria}

Willing females, age 18-35 years, and regular menstrual cycle were included in the study.

\section{Exclusion criteria}

Subjects not giving consent for the study, menstrual disorders, acute, or chronic abdominal pain related to surgical or medical illness, diabetes mellitus, hypertension, cardiovascular disease, syncopal spells, giddiness on standing, steroid therapy, or any other drugs that may alter the sympathetic response, subject receiving psychiatric treatment, smoking, alcohol, or any other recreational drug were excluded from the study. Dropouts were also excluded from the study.

\section{Study tools}

A Menstrual Distress Questionnaire was used to evaluate physical, emotional, and behavioral symptoms accompanying the menstrual cycle ${ }^{8}$ of the subjects who fulfilled the inclusion criteria. Based on the scores obtained by their questionnaire, the subjects were classified into two groups. Subjects who reported at least one of the affective and somatic symptoms during the 5 days before menses in each of the three prior menstrual cycles served as PMS group, while the age-matched females with low scores in the Menstrual Distress Questionnaire served as controls. ${ }^{9}$ The sample size was calculated using a formula for a quantitative observational study. ${ }^{10}$

Details regarding family history of hypertension, coronary artery disease, and sudden cardiac death were obtained. General examination including measurement of weight and height and systemic examination was done. After detailed history and physical examination, the participants were assessed for the menstrual cycle phase by the date of onset of menstruation.

- Premenstrual phase - 5 days before the due date of menses.

- Postmenstrual phase - 5-10 days of the menstrual cycle. 


\section{Study techniques}

Cardiac autonomic neuropathy is diagnosed by tests of autonomic reactivity based on Ewing's criteria. ${ }^{11}$ Cardiovascular sympathetic functions were assessed by standardized, simple, non-invasive tests using sympathetic reflexes. Sympathetic functions of the participants were tested during the follicular and late luteal phases and followup assessments were made during both the phases for three consecutive cycles and the average of three values was taken as final reading for that test. Each test was performed under thermoneutral conditions and at the same time of day in all the subjects. The tests were conducted according to the recommended protocol used in clinical studies. ${ }^{11,12}$ The subjects abstained from coffee, tea, or cola for $6 \mathrm{~h}$ before the study. A light breakfast was allowed $2 \mathrm{~h}$ before tests. All the measurements were performed between $11.30 \mathrm{am}$ and $2.30 \mathrm{pm}$, after recruiting the PMS patients from the gynecology clinic of the associated hospital. The tests were performed in an isolated autonomic function laboratory of the Physiology Department, the temperature of which was maintained between $25^{\circ} \mathrm{C}$ and $27^{\circ} \mathrm{C}$.

The weight of subjects was recorded using the classical weighing machine. Height was measured by stadiometer to nearest $1 \mathrm{~cm}$ and weight by weighing machine (Krups) to the nearest $1 \mathrm{~kg}$ with subjects standing without shoes and wearing light clothes. After a rest for $15 \mathrm{~min}$ basal HR, systolic BP (SBP) and diastolic BP (DBP) was recorded. An electronic automatic ECG recording machine (ASPEN) was used to record lead II ECG and HR. Other apparatus used for tests included timer, automatic BP recording machine (OMARON), and Handgrip dynamometer (25 kg model, IMI, Delhi). Basal BP and HR were measured in the supine position after taking a rest for $5 \mathrm{~min}$.

Tests for a sympathetic component of the autonomic system

\section{$B P$ response to standing lorthostatic hypotension} test)

The subject was asked to take a rest for $5 \mathrm{~min}$ in the supine position, and then to stand up immediately remaining still, when instructed to do so. BP was recorded immediately and then at $30 \mathrm{~s}$ intervals for 2 min or till BP returns to normal. The difference between readings of SBP in the supine position and standing position was calculated. The highest fall in SBP was taken as a response to the test. The fall in SBP more than and equal to $30 \mathrm{mmHg}$ is abnormal. ${ }^{8}$

\section{$B P$ response to sustained hand grip}

Basal BP was recorded in a sitting position and then the participant was asked to perform maximum grip of the handgrip dynamometer with her dominant hand and the maximum capacity was noted (Maximum voluntary contraction).
After a rest of $5 \mathrm{~min}$, she was again asked to hold her grip with $30 \%$ of her maximum voluntary contraction capacity for 2 min. The BP was recorded simultaneously from the non-exercising arm at the $1^{\text {st }}$ and $2^{\text {nd }}$ min followed by releasing of grip and recording of the BP in the $4^{\text {th }}$ min. The highest difference between the rises in DBP just after the release of the grip to the basal DBP was taken as the test response. An increase in diastolic pressure $\leq 10 \mathrm{mmHg}$ is abnormal. ${ }^{11,12}$

\begin{tabular}{lccc}
\hline Test & Normal & Borderline & Abnormal \\
\hline BP response to & $<10 \mathrm{~mm} \mathrm{Hg}$ & $11-29 \mathrm{~mm}$ & $>30 \mathrm{~mm}$ \\
standing (fall in & & $\mathrm{Hg}$ & $\mathrm{Hg}$ \\
systolic BP) & & & \\
BP response to & $>16 \mathrm{~mm} \mathrm{Hg}$ & $11-15 \mathrm{~mm}$ & $<10 . \mathrm{mm}$ \\
sustained handgrip & & $\mathrm{Hg}$ & $\mathrm{Hg}$ \\
(increase in & & & \\
diastolic BP) & & & \\
\hline
\end{tabular}

Ewing's classification of cardiac sympathetic functions into normal, borderline, and abnormal. ${ }^{12}$

\section{Statistical analysis of data}

All the results were expressed in mean \pm S.D. and compared with the control group. The data were analyzed by Statistical Product and Service Solution software for windows and Microsoft Excel. Unpaired Student's t-test was used to find out the level of significance between the two groups. $\mathrm{P}<0.05$ was considered statistically significant.

\section{RESULTS}

A comparative study of resting HR, SBP, and DBP showed no significant difference between cases and control groups in either phase of the menstrual cycle (Table 1).

Sympathetic responses between control and PMS groups during the follicular phase exhibits an increase in sympathetic activity in the PMS group as compared to control ones though there was no statistically significant difference (as the $\mathrm{P}>0.05$ ) as per (Table 2).

A comparative study of sympathetic functions during the luteal phase reflected mean values of OHT as 6.00 2.09 and $10.58 \pm 1.61$ in the control group and case group, respectively, which showed statistically insignificant higher sympathetic responses in premenstrual cases $(\mathrm{P}=1.97)$. HGT responses in the luteal phase indicate a highly statistically significant $(\mathrm{P}=0.0001)$ increase in sympathetic activity in premenstrual cases, with mean values of $12.75 \pm 3.32$ and $16.85 \pm 3.5$ in control group and cases (Table 3).

The results revealed that the sympathetic reactivity is insignificantly higher in the PMS group during the follicular 


\begin{tabular}{|c|c|c|c|c|}
\hline & \multicolumn{2}{|c|}{ Follicular phase } & \multicolumn{2}{|c|}{ Luteal phase } \\
\hline & Cases & Control & Cases & Control \\
\hline $\mathrm{SBP}(\mathrm{mm} \mathrm{Hg})$ & $115.91 \pm 7.30$ & $116.5 \pm 5.47$ & $117.08 \pm 6.77$ & $117.2 \pm 5.15$ \\
\hline $\mathrm{DBP}(\mathrm{mm} \mathrm{Hg})$ & $74.41 \pm 5.98$ & $77.24 \pm 6.91$ & $75.25 \pm 5.10$ & $77.24 \pm 6.37$ \\
\hline HR (beats/min) & $77.66 \pm 5.67$ & $76 \pm 6.16$ & $78.08 \pm 6.05$ & $75.33 \pm 5.37$ \\
\hline
\end{tabular}

\begin{tabular}{|c|c|c|c|}
\hline \multirow{2}{*}{$\begin{array}{l}\text { Sympathetic function } \\
\text { parameters }\end{array}$} & \multicolumn{3}{|c|}{ Follicular phase } \\
\hline & $\begin{array}{l}\text { Control } \\
(n=21)\end{array}$ & $\begin{array}{c}\text { Cases } \\
(n=24)\end{array}$ & $P$ value \\
\hline $\mathrm{OHT}(\mathrm{mm} \mathrm{Hg})$ & $5.04 \pm 2.15$ & $6.08 \pm 2.24$ & 0.12 \\
\hline HGT (mm Hg) & $17.33 \pm 2.39$ & $17.50 \pm 4.38$ & 1.95 \\
\hline
\end{tabular}

\begin{tabular}{|c|c|c|c|}
\hline $\begin{array}{l}\text { Sympathetic function } \\
\text { parameters }\end{array}$ & $\begin{array}{l}\text { Control } \\
(n=21)\end{array}$ & $\begin{array}{l}\text { Cases } \\
(n=24)\end{array}$ & $P$ value \\
\hline OHT $(\mathrm{mm} \mathrm{Hg})$ & $\begin{array}{c}6.00 \pm 2.09 \\
12.75 \pm 3.52\end{array}$ & $\begin{array}{c}10.58 \pm 1.61 \\
16.85 \pm 3.5\end{array}$ & $\begin{array}{c}1.97 \\
0.0001\end{array}$ \\
\hline
\end{tabular}

phase. During the luteal phase, sympathetic activity is significantly increased.

Considering the number of females falling in the normal, borderline, and abnormal category of sympathetic function test in PMS case group (Figure 1), abnormal values are obtained in only one case in Handgrip test and 11 cases showed borderline test results. In reference to the orthostatic hypotension test, about four cases got borderline values and none got abnormal values.

\section{DISCUSSION}

PMSs are characterized by physical and/or affective symptoms that occur in the luteal phase of the menstrual cycle. PMS affects about $25 \%$ of women with a regular menstrual cycle, depending on the strictness of the criteria. ${ }^{9}$ Changes in the autonomic function may be responsible for some of the symptoms produced through endorphins and have been held responsible for behavioral changes. ${ }^{13,14}$ According to Tamaki, women with a greater degree of premenstrual distress possess higher sympathetic activity in the late luteal phase than women with fewer symptoms. ${ }^{15}$ Stimuli that raise BP, such as isometric exercise, or mental arithmetic, activate mainly sympathetic outflow. ${ }^{16}$ The present study investigated differences in sympathetic responses between the "baseline" follicular and the premenstrual phases among the premenstrual cases and controls. Table 1 gives the resting HR, SBP, and DBP of

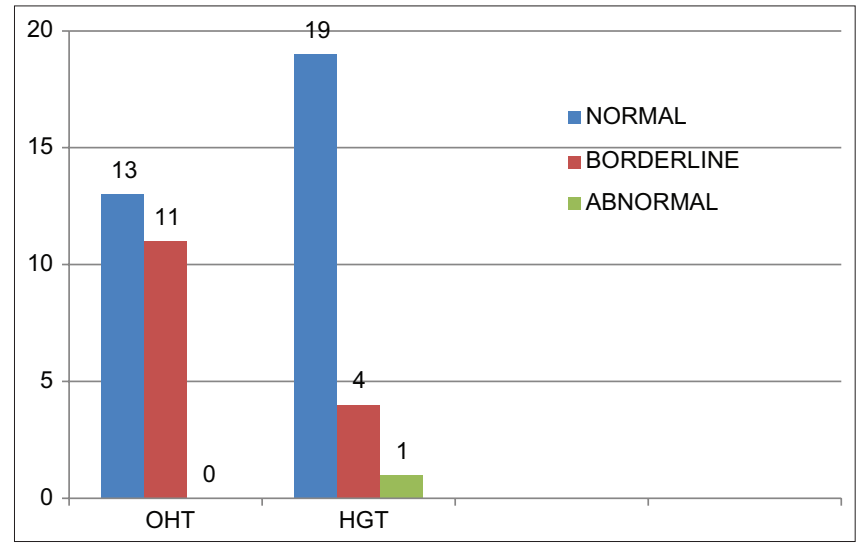

Figure 1: Number of females of premenstrual syndrome showing normal, borderline, and abnormal values in sympathetic autonomic function tests according to Ewing's classification of values of cardiac autonomic function tests

cases and control groups in follicular and luteal phases of the cycles, respectively. Some studies ${ }^{17,18}$ reported a statistically significant rise in systolic and DBP in females with PMS. ${ }^{17}$ However, our study is not in concordance with other researchers as no significant difference was observed in these parameters between cases and control groups in either phase of the menstrual cycle. The difference in results could be due to the large sample size in other studies as compared to our study.

PMS involves altered activity of the sympathetic nervous system in the late luteal phase of the menstrual cycle. Various studies show that sympathetic functions are altered in PMS and our study suggests the same. Matsumoto found that the ANS activity in the follicular phase did not differ among the subjects regardless of their premenstrual symptoms ${ }^{16}$ Girdler et al., ${ }^{19}$ revealed that women with PMS had significantly elevated norepinephrine and total peripheral resistance during both phases as compared with control subjects. Although most studies do not comment on the follicular phase, the present work demonstrated insignificantly higher basal sympathetic activity in the PMS group than the control group during the follicular phase $(\mathrm{P}>0.05)$ as per (Table 2). Ozisik et al., observed no statistical difference in the sympathetic response during the luteal phase between the PMS patients and the control group. ${ }^{20}$ Assoc and Magos investigated that the patient's premenstrual distress appeared to arise mainly 
from chronically high autonomic activity. ${ }^{4}$ Koeske found a premenstrual increase in skin conductance, a test to measure the sympathetic axis. ${ }^{21}$ Matsumoto found that women with PMS exhibit high sympathetic activity during the luteal phase. ${ }^{19}$ Despite the differences in experimental designs and conditions, earlier investigations $s^{4,19,21}$ are in coherence with our findings, indicating that the occurrence of premenstrual symptomatology could be attributable to the uplifted sympathetic axis in the symptomatic late luteal phase. During the luteal phase, there was a significant increase in sympathetic activity in the PMS group as compared to the control group $(\mathrm{P}<0.001)$ (Table 3$)$. Stress in any form is associated with an increase in HR and BP reflecting an uplifted sympathetic axis. It is conceivable that increased sympathetic functions in the luteal phase are associated with the cluster of symptoms appearing premenstrually. Moreover, PMS has a multicausal origin; a definite etiopathological cause remains elusive and needs further investigations.

A study of the classification of sympathetic functions into normal, borderline, and abnormal is according to Ewing's criteria. About $54 \%$ of cases showed a normal range in comparison to $56 \%$ abnormal results in HGT. OHT showed $79 \%$ in the normal range. The mechanisms by which cardiac autonomic function among PMS females may be affected involve psychoneuroendocrinal pathways. Altered activity of the hypothalamus-pituitary-adrenal cortex axis and lifestyle factors may contribute to the hyperactive sympathetic system and cluster of symptoms. Prompt identification of these persons will help in early intervention by behavior therapy, relaxation techniques, and pharmacotherapy to prevent long term cardiovascular hazards.

\section{Strength of study}

Our study suggests that females with PMS have elevated sympathetic responses. We can identify subclinical autonomic reactivity in PMS patients by doing cardiac autonomic function tests, so persons at risk of developing the cardiovascular disease may be recognized at the earliest and can be treated appropriately to improve their quality of life.

\section{Limitations of the study}

Due to time and fiscal constrain, a small sample size was taken which reduced the statistical power of the study to a certain extent. Thus, a study including a greater number of subjects along with a wider age group range is recommended to further assess the sympathetic status.

\section{CONCLUSION}

The study results revealed that patients with PMS suffer from an exaggerated sympathetic response state which manifests as the altered response in sympathetic function tests. As PMS involves a psychoneuroendocrinal turmoil, early screening of high-risk groups and implementing interventions such as relaxation techniques and lifestyle modification can prevent further cardiovascular complications in the patients of high sympathetic responses.

\section{ACKNOWLEDGMENT}

The authors thanks the volunteers who participated in the study.

\section{REFERENCES}

1. Freeman EW. Premenstrual syndrome and premenstrual dysphoric disorder: Definitions and diagnosis. Psychoneuroendocrinology. 2003;28 Suppl 3:25-37. https://doi.org/10.1016/s0306-4530(03)00099-4

2. Wittchen HU, Becker E, Lieb R and Krause P. Prevalence, incidence and stability of premenstrual dysphoric disorder in the community. Psychol Med. 2002;32(10):119-132. https://doi.org/10.1017/s0033291701004925

3. Palmero F and Choliz MJ. Resting heart rate (HR) in women with and without premenstrual symptoms (PMS). Behav Med. 1991;14(2):125-139. https://doi.org/10.1007/bf00846175

4. Asso D and Magos A. Psychological and physiological changes in severe premenstrual syndrome. Biol Psychol. 1992;33(23):115-132. https://doi.org/10.1016/0301-0511(92)90027-r

5. Woods NF, Lentz MJ, Mitchell ES and Kogan H. Arousal and stress response across the menstrual cycle in women with three perimenstrual symptom patterns. Res Nurs Health. 1994;17(2):99-110. https://doi.org/10.1002/nur.4770170205

6. van den Akker $\mathrm{O}$ and Steptoe A. Psychophysiological responses in women with premenstrual and menstrual symptoms. J Psychophysiol. 1987;1:149-158.

7. Cronje WH and Studd JW. Premenstrual syndrome and premenstrual dysphoric disorder. Prim Care. 2002;29(1):1-12. https://doi.org/10.1016/s0095-4543(03)00070-8

8. Moos $\mathrm{RH}$. The development of a menstrual distress questionnaire. Psychosom Med. 1968;30(6):853-867.

9. Swart P and Dreyer G. Premenstrual syndromes-an approach to diagnosis and treatment. S A Fam Pract. 2007;49(3):20-22. https://doi.org/10.1080/20786204.2007.10873527

10. Cohen J. Statistical Power Analysis for the Behavioral Sciences. $2^{\text {nd }}$ ed. London: Lawrence Erlbaum Associates; 1988. p. 550.

11. Ewing DJ and Clarke BF. Diagnosis and management of diabetic autonomic neuropathy. $\mathrm{Br}$ Med $\mathrm{J}$ (Clin Res Ed). 1982;285(6346):916-918. https://doi.org/10.1136/bmj.285.6346.916

12. Ewing DJ. Cardiovascular reflexes and autonomic neuropathy. Clin Sci Mol Med. 1978;55(4):321-327. https://doi.org/10.1042/cs0550321

13. Mehta $V$ and Chakrabarty AS. Autonomic functions during different phases of menstrual cycle. Indian J Physiol Pharmacol. 1993;37(1):56-58. 
14. Saeki Y, Atogami F, Takahashi K and Yoshizawa T. Reflex control of autonomic function induced by posture change during the menstrual cycle. J Auton Nerv Syst. 1997;66(1-2):69-74.

https://doi.org/10.1016/s0165-1838(97)00067-2

15. Matsumoto $\mathrm{T}$, Ushiroyama $\mathrm{T}$, Morimura $\mathrm{M}$, Moritani $\mathrm{T}$, Hayashi T, Suzuki $T$, et al. Autonomic nervous system activity in the late luteal phase of eumenorrheic women with premenstrual symptomatology. J Psychosom Obstet Gynaecol. 2006;27(3):131-139.

https://doi.org/10.1080/01674820500490218

16. Zygmunt A and Stanczyk J. Methods of evaluation of autonomic nervous system function. Arch Med Sci. 2010;6(1):11-18.

17. Okeahialam BN, Obindo JT and Ogbonna C. Prevalence of premenstrual syndrome and its relationship with blood pressure in young adult females. Afr J Med Med Sci. 2008;37(4):361-367.

18. Bertone-Johnson ER, Houghton SC, Whitcomb BW, Sievert LL, Zagarins SE and Ronnenberg AG. Association of premenstrual syndrome with blood pressure in young adult women. J Womens Health (Larchmt). 2016;25(11):1122-1128.

https://doi.org/10.1089/jwh.2015.5636

19. Girdler SS, Pedersen CA, Straneva PA, Leserman J, Stanwyck CL, Benjamin S, et al. Dysregulation of cardiovascular and neuroendocrine responses to stress in premenstrual dysphoric disorder. Psychiatry Res. 1998;81(2):163-178. https://doi.org/10.1016/s0165-1781(98)00074-2

20. Ozisik HI, Kamisli O, Karlidag R, Kizkin S and Ozcan C. Sympathetic skin response in premenstrual syndrome. Clin Auton Res. 2005;15(3):233-237. https://doi.org/10.1007/s10286-005-0281-8

21. Koeske R. Theoretical perspectives on menstrual cycle research: The relevance of attributional approaches for the perception and explanation of premenstrual emotionality. In: The Menstrual Cycle: A Synthesis of Interdisciplinary Research. Vol. 1. New York: Springer; 1980. p. 54.

\section{Authors' Contributions:}

MK - Concept and Design; NG - Interpretation of results, review; VG - Manuscript preparation and revision of manuscript; SRK- Concept, Co-ordination, Statistical analysis.

Work attributed to:

Subharti Medical College, Meerut, Uttar Pradesh, India.

Orcid ID:

Dr. Megha Kulshreshtha - (D) https://orcid.org/0000-0002-6655-6218

Dr. Naveen Gaur - (1) https://orcid.org/0000-0002-0822-2295

Dr. Varuna Gupta - (1) https://orcid.org/0000-0002-4083-0645

Dr. Satyanath Reddy Kodidala - (i) https://orcid.org/0000-0001-7830-7211

Source of Funding: None, Conflicts of Interest: None. 